\title{
FSME: Ungewöhnliche Fälle und Übertragungswege
}

\author{
Aktuelle Zahlen des Robert Koch-Instituts (RKI) zeigen, dass 2016 in Deutschland mit \\ 344 besonders viele Fälle der Frühsommer-Meningoenzephalitis (FSME) gemeldet wurden. \\ Im Vergleich zum Vorjahr gab es einen Anstieg 56\% (221 Fälle). Schlimm genug - aber den \\ Wissenschaftlern bereiten noch weitere Vorkommnisse einigen Kummer.
}

Die ersten gesicherten FSME-Fälle in Deutschland, bei denen sich die beiden Erkrankten (Vater und Sohn) durch den Verzehr von Ziegenkäse infiziert hatten; die erste nachgewiesene FSME-Erkrankung durch eine infizierte Auwaldzecke vom Typ Dermacentor reticulatus, der bisher als absolut frei von FSME-Viren galt; der erste FSME-Fall in den Niederlanden, wo die Erkrankung bislang noch nie aufgetreten war. Alle diese Ereignisse treiben PD Dr. med. Gerhard Dobler, Leiter der Abteilung für Virologie und Rickettsiologie am Institut für Mikrobiologie der Bundeswehr München, die Sorgenfalten auf die Stirn. Der Facharzt für Mikrobiologie, Virologie und Infektionsepidemiologie leitet seit 2015 das deutsche Konsiliarlabor für FSME.

Ständig gibt es neue Endemiegebiete und der Trend der FSME-Erkrankungen zeigt nach oben. Dass 2016 diesbezüglich kein Rekordjahr wurde, ist Dobler zufolge ausschließlich der Tatsache geschuldet, dass der sonst übliche Herbstpeak letztes

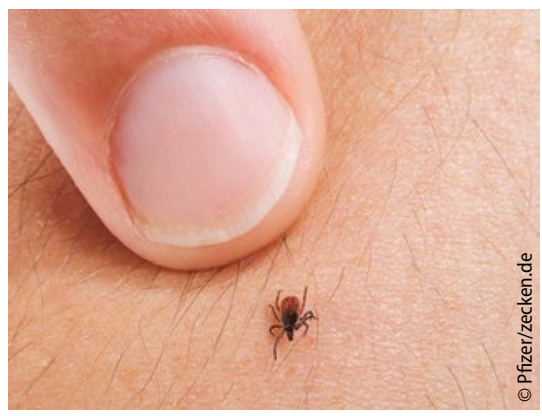

Icodes ricinus auf der Haut.
Jahr ausfiel. Die Gründe? Unbekannt! Auf keinen Fall habe dies etwas mit der Durchimpfungsrate gegen die FSME zu tun, legt sich der Experte fest: Die sei in Deutschland nämlich beklagenswert schlecht und nehme zudem ab statt zu.

\section{Impfbereitschaft mangelhaft}

Die geringe Impfbereitschaft bedauert auch Dr. med. Johannes P. Borde, Infektiologe aus Oberkirch. Zwar bricht die Erkrankung nur bei rund einem Drittel der mit dem FSME-Virus-Infizierten tatsächlich aus, aber dann sind immer wieder schwere und auch tödliche Verläufe (1\% der Patienten mit ZNS-Beteiligung) $\mathrm{zu}$ beobachten. Unterschätzt werden auch die lange Rekonvaleszenz - ein Jahr ist nicht die Ausnahme, sondern eher die Regel - und die hohe Rate (über 60\%) langwieriger, gar dauerhafter neurologischer Defizite (Lähmungen, Gleichgewichtsstörungen, Kopfschmerzen, Fatigue, kognitive Störungen etc.) nach überstandener FSME-Erkrankung.

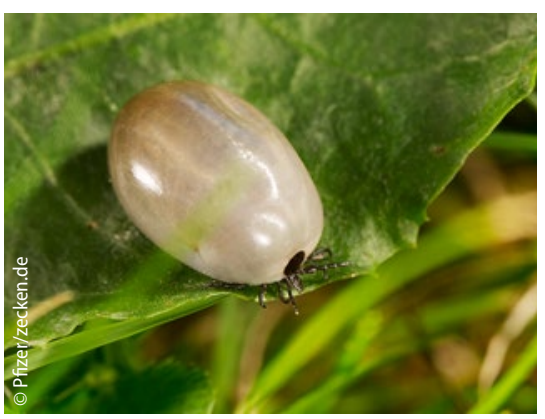

Mit Blut vollgesaugte Zecke im Grünen.

\section{Biphasischer Verlauf}

Die FSME verläuft typischerweise biphasisch:

Phase 1 - Ein bis zwei (max. vier) Wochen nach dem Zeckenstich zeigen Erkrankte unspezifische, grippeähnliche Symptomen. Serologie und Liquorbefunde sind in dieser Zeit nicht diagnoseweisend.

Phase 2 - An ein beschwerdefreies Intervall von ein bis drei Wochen schließt sich bei einem Teil der Patienten eine zweite Phase an. Sie manifestiert sich

- bei 50\% der Betroffenen als Meningitis mit Fieber, Schwindel, starken Kopf- und Nackenschmerzen,

- bei $40 \%$ als Meningoenzephalitis mit zusätzlichen Symptomen wie Lähmungen, Bewusstseins- und Koordinationsstörungen,

- bei $10 \%$ als Meningoenzephalomyelitis mit Lähmungen der Extremitäten- und Atemmuskulatur.

Bis heute kann die manifeste FSME nur symptomatisch behandelt werden. Oft ist eine langwierige und teure intensivmedizinische Betreuung erforderlich.

Den laut RKI „zuverlässigsten Schutz“ vor einer FSME-Erkrankung bietet die Impfung. Die Ständige Impfkommission (STIKO) empfiehlt sie allen Personen, die sich in FSME-Risikogebieten aufhalten und dort in Beruf oder Freizeit zeckenexponiert sind.

Dr. Brigitta Schneider

- Pressegespräch „FSME - die unterschätzte Gefahr: höhere FSME-Zahlen 2016 versus stagnierende Impfraten"; München, 7. März 2017 (Veranstalter: Pfizer) 